\title{
Nutrition in Patients with Gastric Cancer: An Update
}

\author{
Rosa Rosania $^{a} \quad$ Costanza Chiapponi $^{\mathrm{b}}$ Peter Malfertheiner ${ }^{\mathrm{a}}$ \\ Marino Venerito ${ }^{a}$ \\ Departments of a Gastroenterology, Hepatology and Infectious Diseases and \\ ${ }^{b}$ General, Visceral and Vascular Surgery, Otto-von-Guericke University Magdeburg, \\ Magdeburg, Germany
}

\section{Key Words}

Gastric cancer · Nutritional management

\begin{abstract}
Background: Nutritional management of patients with gastric cancer (GC) represents a challenge. Summary: This review provides an overview of the present evidence on nutritional support in patients with GC undergoing surgery as well as in those with advanced disease. Key Message: For patients undergoing surgery, the preoperative nutritional condition directly affects postoperative prognosis, overall survival and disease-specific survival. Perioperative nutritional support enriched with immune-stimulating nutrients reduces overall complications and hospital stay but not mortality after major elective gastrointestinal surgery. Early enteral nutrition after surgery improves early and long-term postoperative nutritional status and reduces the length of hospitalization as well. Vitamin $B_{12}$ and iron deficiency are common metabolic sequelae after gastrectomy and warrant appropriate replacement. In malnourished patients with advanced GC, short-term home complementary parenteral nutrition improves the quality of life, nutritional status and functional status. Total home parenteral nutrition represents the only modality of caloric intake for patients with advanced GC who are unable to take oral or enteral nutrition. Practical Implications: Early evaluations of nutritional status and nutritional support represent key aspects in the management of GC patients with both operable and advanced disease.




\section{Introduction}

Despite its declining incidence over the last several decades, gastric cancer (GC) remains the fifth most common malignancy in the world and the third leading cause of cancer death in both sexes worldwide [1]. GC is often asymptomatic, or it may cause only nonspecific symptoms in its early stages, which is one of the main reasons for the often delayed diagnosis [2] and its relatively poor prognosis [3].

Weight loss is reported for $31-87 \%$ of patients at first diagnosis of malignancy, and the scope of weight loss depends directly on the type of cancer [4]. In particular, a weight loss $>10 \%$ within the previous 6 months is observed in 15\% of patients diagnosed with gastroesophageal cancer, whereas malnutrition occurs in up to $80 \%$ of GC patients in an advanced stage $[5,6]$.

The anorexia-cachexia syndrome [7, 8], commonly described in patients with advanced cancer, is characterized by decreased food intake, hypoalbuminemia, weight loss and muscle tissue wasting and is associated with increased morbidity and mortality [9-11]. In GC patients, this condition is mainly caused by obstruction of the upper digestive tract due to the mechanical effects of the tumor [12]. Dysphagia, early satiety, nausea and vomiting may follow. For patients with GC, the anorexia-cachexia syndrome is associated with shortened overall survival [13]. Together with symptoms such as nausea, vomiting, early satiety and dysphagia following chemotherapy, radiotherapy or surgery, this condition may contribute to cancerrelated malnutrition [14-16]. Thus, identifying and treating malnutrition early in the course of GC is critical for improving patient outcomes.

\section{Nutritional Treatment}

The goal of the nutritional therapy is to improve the nutritional status, metabolism, adherence to antitumoral therapies, quality of life and course of the disease [17]. Nutritional support is recommended for both GC patients undergoing surgery and those with unresectable disease and could be performed with oral, enteral (EN) and parenteral nutrition (PN). Oral nutrition includes diet and oral supplementation. After gastrectomy, a diet based on frequent small meals with limitation of simple carbohydrates, in order to prevent dumping syndrome, is recommended. EN (nourishment into the gut) is variably defined and may include diet, oral supplementation and feeding via a tube. For the present review, EN is specified as feeding by tube and includes percutaneous endoscopic gastrostomy, percutaneous radiologic gastrostomy and percutaneous endoscopic jejunostomy. EN preserves the structural and functional integrity of the gastrointestinal tract and represents a valid nutritional option for patients with dysphagia or obstruction when the oral intake does not satisfy the nutritional requirements [18]. EN is safer, cheaper and more physiological than PN. However, in patients with impaired gastrointestinal function, PN is mandatory. Although PN (nourishment by central and peripheral veins) ensures optimal nutrition, it increases the risk of infections when compared to EN [19]. Catheter-related bloodstream infection is the most common and serious complication in adult patients receiving PN. In a systematic review of 39 studies, the overall catheter-related bloodstream infection rate ranged between 0.4 and 4.6 episodes/1,000 catheter days (median 1.3) in patients with home PN (HPN), and was mostly related to Gram-positive bacteria of the human skin flora [20]. Thus, in terminal-stage disease the benefit of nutritional support may be limited and associated with an increased risk of complications. As a consequence, the recent German S3 Guidelines recommend nutritional support only when benefits prevail over any possible complications or when desired by patients [17]. 


\section{Evaluation of Nutritional Status}

An evaluation of nutritional status, food intake and the severity of the disease should be performed starting with first contact on a regular basis and at short time intervals (at least every 4-8 weeks) to recognize any reduction of nutritional status as early as possible [17]. Several questionnaires have been developed for the early detection and treatment of malnourished hospital patients [21,22]. In particular, increased scores on the Nutritional Risk Screening 2002 (NRS 2002) tool are associated with increased rates of postoperative complications and increased length of stay [23]. Furthermore, in a recent study evaluating the efficacy of the Short Nutritional Assessment Questionnaire (SNAQ) in predicting the risk of postoperative mortality after GC surgery, a SNAQ score $\geq 1$ was associated with an increased mortality rate compared to a SNAQ score of 0 (OR $=5.1 ; 95 \% \mathrm{CI}$ : 1.01-23.8) [24].

In a recent retrospective study on 775 patients who underwent gastrectomy for GC, the body mass index (BMI) alone did not impact perioperative morbidity or recurrence-free or overall survival [25]. However, patients with a BMI $<18.5$ and low preoperative albumin levels had significantly decreased overall survival after gastrectomy.

Different indices have been proposed to predict the prognosis of patients with gastrointestinal malignancies $[26,27]$. In particular, the prognostic nutritional index (PNI) has been widely used, due to its efficiency, simplicity and convenience [28]. The PNI is calculated using the following formula: $10 \times$ serum albumin value $(\mathrm{g} / \mathrm{dl})+0.005 \times$ lymphocyte count in peripheral blood. A score $<45$ is indicative of severe nutritional impairment, whereas a PNI $\geq 45$ is associated with normal nutritional status. In a recent meta-analysis, PNI was associated with depth of invasion and lymph node metastasis in GC [29]. Sakurai et al. [30] showed that in patients with GC, the preoperative PNI is an independent predictive factor for both overall survival and disease-specific survival. Notably, the patients with UICC stage 1 and 2 disease had significantly worse outcomes in the low-PNI group than in the high-PNI group. To sum up, the following may be stated:

- Preoperative nutritional support may improve postsurgical outcome in patients undergoing surgery for GC

- Several validated questionnaires for the early detection and treatment of malnourished hospital patients are available

- The PNI, or the combination of a preoperative BMI <18.5 and low albumin levels, is predictive of decreased overall survival after gastrectomy

\section{Preoperative Nutrition}

For patients undergoing major surgery, preoperative malnutrition is associated with increased morbidity (i.e. increased infection rate, delayed wound healing and pulmonary complications, including adult respiratory distress syndrome) and mortality [31-33]. Thus, improving the nutritional status before surgery may ameliorate the postsurgical outcome of GC patients. The German S3 Guidelines recommend nutritional support for all patients with insufficient dietary intake [17]. This condition is defined as an oral food intake $<500 \mathrm{kcal} /$ day or $\leq 75 \%$ of the requirement for more than 1-2 weeks [34]. In an intact gastrointestinal tract, EN is as effective as PN [35]. EN may be performed through a nasogastric or a nasoenteric tube for short periods, whereas direct access to the bowel such as via a jejunostomy should be preferred if EN is given for $>3$ weeks [36]. Recently, a randomized controlled trial (RCT) on 106 patients undergoing gastrectomy for GC demonstrated that preoperative EN improves the postoperative nutritional status, alleviates the inflammatory response and facilitates the 


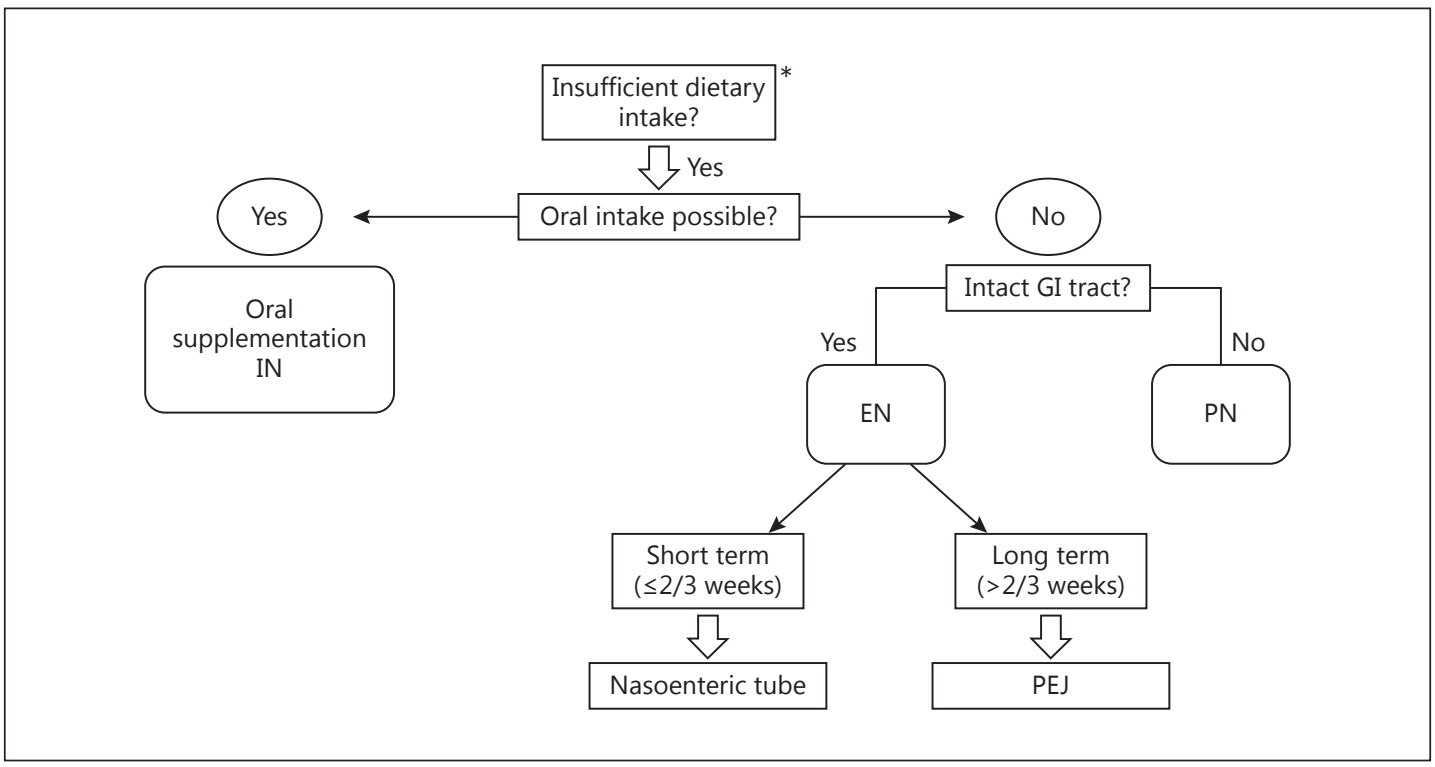

Fig. 1. Decision algorithm for the delivery route of perioperative nutrition in patients undergoing surgery for GC. * Oral food intake $<500 \mathrm{kcal} /$ day or $\leq 75 \%$ of the requirement for more than $1-2$ weeks [17]. GI = Gastrointestinal; $\mathrm{PEJ}=$ percutaneous endoscopic jejunostomy.

recovery of patients [37]. Nutritional support via PN may be required for patients with a nonfunctional or inaccessible gastrointestinal tract [38].

Oral or enteral administration of a nutritional solution enriched with immune-stimulating nutrients (arginine, $\omega-3$ fatty acids and nucleotides) is called immunonutrition (IN) [39]. In a recent meta-analysis of 9 studies, the immunological impact of enteral IN was evaluated in patients undergoing surgery for GC [40]. Compared to standard EN, IN enhanced the host immunity by increasing the level of immunoglobulins, T-helper 17 cells and natural killer cells and decreasing the level of proinflammatory cytokines such as IL- 6 and TNF- $\alpha$. Another meta-analysis based on 21 RCTs compared perioperative IN to standard EN in patients undergoing major elective gastrointestinal surgery. Perioperative IN significantly reduced overall complications and hospital stay but not mortality [41]. Accordingly, the ESPEN Guidelines, the German S3 Guidelines [17] for GC and the North American Surgical Nutrition Summit [42] recommend oral/enteral IN for patients with upper gastrointestinal cancer 5-7 days before surgery and through the postoperative period. Figure 1 displays an algorithm for the delivery route of perioperative nutrition in patients undergoing surgery for GC.

Independently of nutritional status, the Enhanced Recovery after Surgery (ERAS) group has recently provided recommendations for the perioperative holistic management of patients with upper gastrointestinal tumors. They recommend a preoperative carbohydrate loading ( $800 \mathrm{ml}$ of a $12.5 \%$ carbohydrate drink the night before surgery and $400 \mathrm{ml}$ the following morning $2 \mathrm{~h}$ prior to induction of anesthesia) in order to (1) reduce the insulin resistance and tissue glycosylation caused by the surgery, (2) help in postoperative glucose control and (3) sustain normal bowel function [43]. Summing up, one can state the following:

- Perioperative IN reduces overall complications and hospital stay but not mortality after major elective gastrointestinal surgery

- Preoperative carbohydrate loading during the night before surgery reduces the insulin resistance and tissue glycosylation caused by the surgery, helps in postoperative glucose control and sustains normal bowel function 


\section{Postoperative Nutrition}

The role of postoperative nutritional support is to maintain nutritional status in the catabolic period after surgery. In a prospective study evaluating the perioperative nutritional status of 435 patients with GC, the prevalence of severe malnutrition increased substantially after surgery (2.3 and $26.3 \%$ before and after surgery, respectively) [44]. Older age, preoperative weight loss and open surgery were identified as risk factors for severe postoperative malnutrition.

After surgical treatment, appetite and diet intake decline during recovery and nutritional status can take up to 1 year to recover [45]. Small intestinal functions resume between 6 and $12 \mathrm{~h}$ after surgery, indicating that EN support could be started at that time. In line with this notion, a study by Gabor et al. [46] showed that it is safe to begin EN $6 \mathrm{~h}$ after surgery. Accordingly, patients undergoing upper gastrointestinal surgery are usually provided with a percutaneous jejunostomy tube for postoperative EN, which can be continued also after discharge depending on a patient's needs. Early oral nutrition after surgery for GC is safe as well, and does not increase the incidence of postoperative complications when compared to EN through a nasogastric tube [47]. In an RCT on 105 patients undergoing surgery for gastrointestinal cancer, early postoperative nutritional support reduced surgical trauma-related high metabolism, maintained the function of the intestinal mucosal barrier and decreased the incidence of intestinal-borne infections, improving the recovery of patients [48]. Perioperative nutrition effectively reduces the incidence of postoperative complications in malnourished GC patients. In another RCT, 468 moderately or severely malnourished patients with GC or colorectal cancer were randomly assigned to 7-day preoperative and 7-day postoperative artificial nutrition (EN or PN) and compared to a simple control group. A twofold reduction in postoperative complications and a threefold reduction in deaths were observed among the patients with perioperative nutrition. The most dramatic decrease was noted in major septic complications ( 14.9 vs. $27.9 \%, \mathrm{p}=0.011$ ) such as pneumonia and wound infection [49]. The total length of hospitalization and postoperative stay of the control patients were significantly longer ( 29 vs. 22 days, $p=0.014$ ) than those of the studied patients. In conclusion, the following may be said:

- EN can be safely initiated $6 \mathrm{~h}$ after surgery via a percutaneous jejunostomy tube

- Early postoperative nutrition reduces surgical trauma-related high metabolism, maintains the function of the intestinal mucosal barrier and decreases the incidence of intestinal-borne infections, improving the recovery of patients

\section{Nutritional Supplementation after Gastrectomy}

Anemia is a frequent complication after gastrectomy, and deficiencies in iron, vitamin $B_{12}$ or folate have been reported after gastric surgery. Anemia develops in $50 \%$ of patients who undergo total gastrectomy [50]. Poor nutritional status and decreased dietary iron intake may lead to iron depletion after gastric surgery [51]. Increased iron depletion may also result from gastrointestinal blood loss at the anastomotic site [52] or from bacterial overgrowth in the blind loops [53]. However, alterations in digestion and impaired iron absorption are considered the leading factors contributing to iron deficiency after gastrectomy [54]. Malabsorption of dietary iron possibly results from a reduction of gastric acid secretion and bypassing of the duodenum. Reduced gastric acidity impairs the conversion of nonheme iron $\left(\mathrm{Fe}^{3+}\right)$ into the more absorbable ferrous form $\left(\mathrm{Fe}^{2+}\right)[55]$. The reconstruction after gastrectomy may decrease iron absorption due to bypass of the major sites of iron absorption: the duodenum and the proximal jejunum. 
In a retrospective study on 119 patients who underwent a distal gastrectomy with Billroth I or Roux-en-Y reconstructions for stage I GC, univariate and multivariate analyses showed that Roux-en-Y reconstruction is the only risk factor $(\mathrm{p}=0.0487$; OR $=2.755 ; 95 \%$ CI: 1.01-7.91) for a decrease in hemoglobin [56]. A higher incidence of anemia and iron deficiency has also been reported after total gastrectomy compared to subtotal gastrectomy [57].

The treatment of iron-deficiency anemia after gastrectomy requires correction of the deficit in circulating hemoglobin, replenishment of the storage deficit and correction of any treatable source of abnormal blood loss. Also, prophylactic treatment of the anticipated deficiency with simple preparations, in the form of ferrous sulfate or gluconate, is usually effective [17].

Vitamin $\mathrm{B}_{12}$ deficiency can develop as early as 1 year after total gastrectomy [58]. Intrinsic factor, which is mainly produced by parietal cells of the oxyntic gastric glands, is necessary to absorb enteral vitamin $B_{12}$ [59]. Fischermann et al. [60] demonstrated that the type of reconstruction had no effect on vitamin $B_{12}$ absorption. Thus, passage of food through the duodenum is not necessary for enteral vitamin $B_{12}$ absorption. However, the clinical presentation of postgastrectomy vitamin $\mathrm{B}_{12}$ deficiency has not been clearly defined, nor has the role of supplemental vitamin $B_{12}$ therapy been standardized. In the German S3 guideline [17], supplementation with vitamin $B_{12}$ is recommended after surgery. Administration of vitamin $B_{12}$ is effective both via the subcutaneous and the oral route [61]. Indeed, in a study by Adachi et al. [62] oral vitamin $B_{12}$ supplementation was effective in increasing the serum vitamin $B_{12}$ concentration, with prompt resolution of the symptoms related to vitamin $\mathrm{B}_{12}$ deficiency. Kim et al. [63] demonstrated that oral vitamin $B_{12}$ replacement therapy provides safe and effective treatment for vitamin $B_{12}$ deficiency after total gastrectomy in GC patients. The rationale for this approach is the presence of a second, lower efficiency transport system for vitamin $B_{12}$ that does not require intrinsic factor or a functioning terminal ileum but uses passive diffusion. Thus, prophylactic enteral vitamin $B_{12}$ supplementation after total gastrectomy is a good and convenient alternative to the subcutaneous route for preventing symptoms associated with vitamin $\mathrm{B}_{12}$ deficiency.

Pancreatic insufficiency has been proposed as a possible cause of malabsorption following total gastrectomy [64]. Although pancreatic exocrine insufficiency has been demonstrated after gastrectomy, the key question remains whether pancreatic enzyme supplements may improve the clinical outcome of GC patients. In a prospective, double-blind, randomized, parallel, placebo-controlled multicenter trial, pancreatic enzyme supplementation did not result in a significant difference between a placebo and an enzyme-treated group regarding bowel habits or fat malassimilation [65]. The effect of high-dose pancreatic enzyme supplementation on symptoms and steatorrhea after total gastrectomy was marginal and did not justify a routine use. In summary, one could state the following:

- Anemia develops in $50 \%$ of patients who undergo total gastrectomy

- Malabsorption of dietary iron due to a reduction of gastric acid secretion and bypassing of the duodenum is the main cause of anemia after gastrectomy

- The treatment of iron-deficiency anemia requires correction of the deficit in circulating hemoglobin, replenishment of the storage deficit and correction of any treatable source of abnormal blood loss

- Vitamin $B_{12}$ deficiency can develop as early as 1 year after total gastrectomy

- Current guidelines recommend supplementation with vitamin $\mathrm{B}_{12}$ after gastrectomy

- The effect of high-dose pancreatic enzyme supplementation on symptoms and steatorrhea after total gastrectomy is marginal and does not justify a routine use 


\section{Nutrition in Patients with Advanced GC}

Whenever nutritional support is indicated, the oral and enteral routes are preferred to the parenteral one. In GC patients with stenosis of the cardia or pylorus, the placement of a stent may allow oral nutrition, improving the quality of life. The European Society for Clinical Nutrition and Metabolism guidelines recommend the application of PN when 'an inadequate food intake of less than $60 \%$ of the estimated energy intake for more than ten days can be expected' [19]. For patients on chemotherapy experiencing chemotherapy-related gastrointestinal side effects (i.e. anorexia, nausea, vomiting, constipation and diarrhea), complementary HPN is recommended for weight stabilization and therapy continuation [17]. Furthermore, based on our experience short-term complementary HPN can be provided safely and effectively to patients with weight loss despite an adequate oral intake or oral supplementation (i.e. cancer cachexia) as well as in cases of EN intolerance (i.e. nausea, abdominal pain and diarrhea).

For patients with peritoneal carcinosis and severe impairment of gastrointestinal function, total HPN is mandatory [15]. Short bowel syndrome due to extensive surgery is another indication for HPN [66]. The success of PN depends on patient compliance, support by a professional and committed nutritionist and cooperation between the patient, nutritionist, physician and home care provider [67]. In numerous studies, PN failed to reduce the toxicity of chemotherapy [68] and to improve the response rate [69]. Especially for patients with advanced GC and for those who are not malnourished or hypophagic, the risks of PN may outweigh the benefits [70]. On the other hand, in patients with advanced cancer and moderateto-severe malnutrition HPN improves the quality of life, nutritional status and functional status irrespective of the tumor type [71]. The greatest benefit was seen in patients with 3 months of complementary HPN, although patients receiving HPN for 1 or 2 months also demonstrated significant improvements. To sum up, the following can be stated:

- For patients with advanced GC who are unable to take oral nutrition or EN, total HPN is mandatory

- In patients with advanced GC who are not malnourished or hypophagic, the risks of PN may outweigh the benefits

- In malnourished patients with advanced cancer, short-term complementary HPN is associated with an improvement in quality of life, nutritional status and functional status

\section{Future Directions}

Modern therapy of patients with localized GC suitable for surgery includes neoadjuvant radiochemotherapy and perioperative chemotherapy, which represent sources of catabolic stress and malnutrition. The role of nutritional support during neoadjuvant/perioperative treatment of GC patients is still to be determined. In Europe, a controlled phase III study is currently testing whether IN may improve the quality of life of patients treated with neoadjuvant radiochemotherapy and perioperative chemotherapy for esophagogastric cancers (NCT01423799).

\section{Disclosure Statement}

R.R., C.C., P.M. and M.V. have nothing to disclose. 


\section{References}

1 International Agency for Research on Cancer: GLOBOCAN 2012: estimated cancer incidence, mortality and prevalence worldwide in 2012. http://globocan.iarc.fr/Pages/fact_sheets_cancer.aspx.

-2 Wadhwa R, Taketa T, Sudo K, Blum MA, Ajani JA: Modern oncological approaches to gastric adenocarcinoma. Gastroenterol Clin North Am 2013;42:359-369.

3 Cancer Research UK: Statistics and outlook for stomach cancer. 2014. http://www.cancerresearchuk.org/ about-cancer/type/stomach-cancer/treatment/statistics-and-outlook-for-stomach-cancer.

$>4$ Gupta D, Lis CG, Granick J, Grutsch JF, Vashi PG, Lammersfeld CA: Malnutrition was associated with poor quality of life in colorectal cancer: a retrospective analysis. J Clin Epidemiol 2006;59:704-709.

5 Deans DA, Tan BH, Wigmore SJ, Ross JA, de Beaux AC, Paterson-Brown S, Fearon KCD: The influence of systemic inflammation, dietary intake and stage of disease on rate of weight loss in patients with gastro-oesophageal cancer. Br J Cancer 2009;100:63-69.

6 Ravasco P, Monteiro-Grillo I, Vidal PM, Camilo ME: Cancer: disease and nutrition are key determinants of patients' quality of life. Support Care Cancer 2004;12:246-252.

7 Deans C, Wigmore S: Systemic inflammation, cachexia and prognosis in patients with cancer. Curr Opin Clin Nutr Metab Care 2005;8:265-269.

$>8$ von Haehling S, Anker SD: Cachexia as a major underestimated and unmet medical need: facts and numbers. J Cachexia Sarcopenia Muscle 2010;1:1-5.

-9 Fearon K, Strasser F, Anker SD, Bosaeus I, Bruera E, Fainsinger RL, Jatoi A, Loprinzi C, MacDonald N, Mantovani G, Davis M, Muscaritoli M, Ottery F, Radbruch L, Ravasco P, Walsh D, Wilcock A, Kaasa S, Baracos VE: Definition and classification of cancer cachexia: an international consensus. Lancet Oncol 2011;12:489-495.

-10 Tan CR, Yaffee PM, Jamil LH, Lo SK, Nissen N, Pandol SJ, Tuli R, Hendifar AE: Pancreatic cancer cachexia: a review of mechanisms and therapeutics. Front Physiol 2014;5:88.

$\checkmark 11$ Evans WJ, Morley JE, Argilés J, Bales C, Baracos V, Guttridge D, Jatoi A, Kalantar-Zadeh K, Lochs H, Mantovani G, Marks D, Mitch WE, Muscaritoli M, Najand A, Ponikowski P, Rossi Fanelli F, Schambelan M, Schols A, Schuster M, Thomas D, Wolfe R, Anker SD: Cachexia: a new definition. Clin Nutr 2008;27:793-799.

12 Donohoe C, Ryan A, Reynolds J: Cancer cachexia: mechanisms and clinical implications. Gastroenterol Res Pract 2011;2011:601434.

13 Dewys WD, Begg C, Lavin PT, Band PR, Bennett JM, Bertino JR, Cohen MH, Douglass HO Jr, Engstrom PF, Ezdinli EZ, Horton J, Johnson GJ, Moertel CG, Oken MM, Perlia C, Rosenbaum C, Silverstein MN, Skeel RT, Sponzo RW, Tormey DC: Prognostic effect of weight loss prior to chemotherapy in cancer patients. Eastern Cooperative Oncology Group. Am J Med 1980;69:491-497.

14 Tong H, Isenring E, Yates P: The prevalence of nutrition impact symptoms and their relationship to quality of life and clinical outcomes in medical oncology patients. Support Care Cancer 2009;17:83-90.

15 Shahmoradi N, Kandiah M, Peng L: Impact of nutritional status on the quality of life of advanced cancer patients in hospice home care. Asian Pac J Cancer Prev 2009;10:1003-1009.

16 Van Cutsem E, Arends J: The causes and consequences of cancer-associated malnutrition. Eur J Oncol Nurs 2005;9(suppl 2):S51-S63.

$\checkmark 17$ Arends J, Bertz H, Bischoff SC, Fietkau R, Herrmann HJ, Holm E, Horneber M, Hütterer E, Körber J, Schmid I; DGEM Steering Committee: S3-Guideline of the German Society for Nutritional Medicine (DGEM). Aktuelle Ernahrungsmed 2015;40:1-74.

-18 Weimann A, Braga M, Harsanyi L, Laviano A, Ljungqvist O, Soeters P; DGEM (German Society for Nutritional Medicine), Jauch KW, Kemen M, Hiesmayr JM, Horbach T, Kuse ER, Vestweber KH; ESPEN (European Society for Parenteral and Enteral Nutrition): ESPEN Guidelines on Enteral Nutrition: surgery including organ transplantation. Clin Nutr 2006;25:224-244.

19 Bozzetti F, Arends J, Lundholm K, Micklewright A, Zurcher G, Muscaritoli M; ESPEN: ESPEN Guidelines on Parenteral Nutrition: non-surgical oncology. Clin Nutr 2009;28:445-454.

20 Dreesen M, Foulon V, Spriet I, Goossens G, Hiele M, De Pourcq L, Willems L: Epidemiology of catheter-related infections in adult patients receiving home parenteral nutrition: a systematic review. Clin Nutr 2013;32: $16-26$.

21 Kruizenga H, Seidell J, de Vet H, Wierdsma N, van Bokhorst-de van der Schueren MA: Development and validation of a hospital screening tool for malnutrition: the short nutritional assessment questionnaire (SNAQ $\left.{ }^{\odot}\right)$. Clin Nutr 2005;24:75-82.

22 van Venrooij LM, van Leeuwen PA, Hopmans W, Borgmeijer-Hoelen MM, de Vos R, De Mol BA: Accuracy of quick and easy undernutrition screening tools - Short Nutritional Assessment Questionnaire, Malnutrition Universal Screening Tool, and modified Malnutrition Universal Screening Tool - in patients undergoing cardiac surgery. J Am Diet Assoc 2011;111:1924-1930.

23 Guo W, Ou G, Li X, Huang J, Liu J, Wei H: Screening of the nutritional risk of patients with gastric carcinoma before operation by NRS 2002 and its relationship with postoperative results. J Gastroenterol Hepatol 2010; 25:800-803.

24 Tegels J, de Maat M, Hulsewé K, Hoofwijk A, Stoot J: Value of geriatric frailty and nutritional status assessment in predicting postoperative mortality in gastric cancer surgery. J Gastrointest Surg 2014;18:439-445. 
Ejaz A, Spolverato K, Poultsides G, Fields R, Bloomston M, Cho C, Votanopoulos K, Maithel S, Pawlik T: Impact of body mass index on perioperative outcomes and survival after resection for gastric cancer. J Surg Res 2015; 195:74-82.

Asher V, Lee J, Innamaa A: Preoperative platelet lymphocyte ratio as an independent prognostic marker in ovarian cancer. Clin Transl Oncol 2011;13:499-503.

27 Chua W, Charles KA, Baracos VE, Clarke SJ: Neutrophil/lymphocyte ratio predicts chemotherapy outcomes in patients with advanced colorectal cancer. Br J Cancer 2011;104:1288-1295.

28 Onodera T, Goseki N, Kosaki G: Prognostic nutritional index in gastrointestinal surgery of malnourished cancer patients (in Japanese). Nihon Geka Gakkai Zasshi 1984;85:1001-1005.

29 Nozoe T, Ninomiya M, Maeda T, Matsukuma A, Nakashima H, Ezaki T: Prognostic nutritional index: a tool to predict the biological aggressiveness of gastric carcinoma. Surg Today 2010;40:440-443.

-30 Sakurai K, Ohira M, Tamura T, Toyokawa T, Amano R, Kubo N, Tanaka H, Muguruma K, Yashiro M, Maeda K, Hirakawa K: Predictive potential of preoperative nutritional status in long-term outcome projections for patients with gastric cancer. Ann Surg Oncol 2016;23:525-533.

-31 Rey-Ferro M, Castaño R, Orozco 0, Serna A, Moreno A: Nutritional and immunologic evaluation of patients with gastric cancer before and after surgery. Nutrition 1997;13:878-881.

-32 Sungurtekin H, Sungurtekin U, Balci C, Zencir M, Erdem E: The influence of nutritional status on complications after major intraabdominal surgery. J Am Coll Nutr 2004;23:227-232.

-33 Kuzu MA, Terzioğlu H, Genç V, Erkek AB, Ozban M, Sonyürek P, Elhan AH, Torun N: Preoperative nutritional risk assessment in predicting postoperative outcome in patients undergoing major surgery. World J Surg 2006;30:378-390.

-34 Arends J, Bodoky G, Bozzetti F, Fearon K, Muscaritoli M, Selga G, van Bokhorst-de van der Schueren MA, von Meyenfeldt M; DGEM (German Society for Nutritional Medicine), Zürcher G, Fietkau R, Aulbert E, Frick B, Holm M, Kneba M, Mestrom HJ, Zander A; ESPEN (European Society for Parenteral and Enteral Nutrition): ESPEN Guidelines on Enteral Nutrition: non-surgical oncology. Clin Nutr 2006;25:245-259.

-35 Bozzetti F: Nutritional support in patients with oesophageal cancer. Support Care Cancer 2010;18:S41-S50.

-36 Mariette C, De Botton M, Piessen G: Surgery in esophageal and gastric cancer patients: what is the role for nutrition support in your daily practice? Ann Surg Oncol 2012;19:2128-2134.

-37 Ding D, Feng Y, Song B, Gao S, Zhao J: Effects of preoperative and postoperative enteral nutrition on postoperative nutritional status and immune function of gastric cancer patients. Turk J Gastroenterol 2015;26:181185.

-38 Lipman T: Grains or veins: is enteral nutrition really better than parenteral nutrition? A look at the evidence. JPEN J Parenter Enteral Nutr 1998;22:167-182.

-39 Heyland DK, Novak F, Drover JW, Jain M, Su X, Suchner U: Should immunonutrition become routine in critically ill patients? A systematic review of the evidence. JAMA 2001;286:944-953.

40 Cerantola Y, Hübner M, Grass F, Demartines N, Schäfer M: Immunonutrition in gastrointestinal surgery. Br J Surg 2011;98:37-48.

41 Gianotti L, Braga M, Nespoli L, Radaelli G, Beneduce A, Di Carlo V: A randomized controlled trial of preoperative oral supplementation with a specialized diet in patients with gastrointestinal cancer. Gastroenterology 2002;122:1763-1770.

-42 McClave SA, Kozar R, Martindale RG, Heyland DK, Braga M, Carli F, Drover JW, Flum D, Gramlich L, Herndon DN, Ko C, Kudsk KA, Lawson CM, Miller KR, Taylor B, Wischmeyer PES: Summary points and consensus recommendations from the North American Surgical Nutrition Summit. JPEN J Parenter Enteral Nutr 2013; 37(suppl):99S-105S.

43 Mariette C: Role of the nutritional support in the ERAS programme. J Visc Surg 2015;152(suppl 1):S18-S20.

44 Shim H, Cheong JH, Lee KY, Lee H, Lee JG, Noh SH: Perioperative nutritional status changes in gastrointestinal cancer patients. Yonsei Med J 2013;54:1370-1376.

-45 Ryu SW, Kim IH: Comparison of different nutritional assessments in detecting malnutrition among gastric cancer patients. World J Gastroenterol 2010;16:3310-3317.

-46 Gabor S, Renner H, Matzi V, Ratzenhofer B, Lindenmann J, Sankin O, Pinter H, Maier A, Smolle J, Smolle-Jüttner FM: Early enteral feeding compared with parenteral nutrition after oesophageal or oesophagogastric resection and reconstruction. Br J Nutr 2005;93:509-513.

-47 Hur H, Si Y, Kang WK, Kim W, Jeon HM: Effects of early oral feeding on surgical outcomes and recovery after curative surgery for gastric cancer: pilot study results. World J Surg 2009;33:1454-1458.

-48 Huang D, Sun Z, Huang J, Shen Z: Early enteral nutrition in combination with parenteral nutrition in elderly patients after surgery due to gastrointestinal cancer. Int J Clin Exp Med 2015;15:13937-13945.

-49 Wu GH, Liu ZH, Wu ZH, Wu ZG: Perioperative artificial nutrition in malnourished gastrointestinal cancer patients. World J Gastroenterol 2006;12:2441-2444.

50 Kelly WD, MacLean LD, Perry JF, Wangensteen OH: A study of patients following total and near-total gastrectomy. Surgery 1953;35:964-982.

51 Hines JD, Hoffbrand AV, Mollin DL: The hematologic complications following partial gastrectomy. A study of 292 patients. Am J Med 1967;43:555-569.

52 Kimber C, Patterson JF, Weintraub LR: The pathogenesis of iron deficiency anemia following partial gastrectomy. A study of iron balance. JAMA 1967;202:935-938. 

struction method as an independent risk factor for the postoperative decrease in hemoglobin in stage I gastric cancer. J Gastroenterol Hepatol 2015, Epub ahead of print.

Ba JM, Park JW, Yang HK, Kim JP: Nutriona stau J Surg 1998;22:254-260; discussion 260-261.

59 Okuda K: Discovery of vitamin $\mathrm{B}_{12}$ in the liver and its absorption factor in the stomach: a historical review. J Gastroenterol Hepatol 1999;14:301-308.

60 Fischermann K, Harly S, Worning H, Zacho A: Pancreatic function and the absorption of fat, iron, vitamin $B_{12}$, and calcium after total gastrectomy for gastric cancer. Gut 1967;8:260-266.

61 Bradley EL, Isaacs J: Postresectional anemia. A preventable complication of total gastrectomy. Arch Surg 1976; 111:844-848.

62 Adachi S, Kawamoto T, Otsuka M, Todoroki T, Fukao K: Enteral vitamin $\mathrm{B}_{12}$ supplements reverse postgastrectomy B $\mathrm{B}_{12}$ deficiency. Ann Surg 2000;232:199-201.

-63 Kim HI, Hyung WJ, Song KJ, Choi SH, Kim CB, Noh SH: Oral vitamin B 12 replacement: an effective treatment for vitamin $B_{12}$ deficiency after total gastrectomy in gastric cancer patients. Ann Surg Oncol 2011;18:3711-3717.

64 Gullo L: Indication for pancreatic enzyme treatment in non-pancreatic digestive diseases. Digestion 1993; 54(suppl 2):43-47.

65 Brägelmann R, Armbrecht U, Rosemeyer D, Schneider B, Zilly W, Stockbrügger R: The effect of pancreatic enzyme supplementation in patients with steatorrhoea after total gastrectomy. Eur J Gastroenterol Hepatol 1999;11:231-237.

-66 Winkler MF, Smith CE: Clinical, social, and economic impacts of home parenteral nutrition dependence in short bowel syndrome. JPEN J Parenter Enteral Nutr 2014;38(suppl):32S-37S.

67 Richter E, Denecke A, Klapdor S, Klapdor R: Parenteral nutrition support for patients with pancreatic cancer - improvement of the nutritional status and the therapeutic outcome. Anticancer Res 2012;32:2111-2118.

68 De Cicco M, Panarello G, Fantin D, Veronesi A, Pinto A, Zagonel V, Monfardini S, Testa V: Parenteral nutrition in cancer patients receiving chemotherapy: effects on toxicity and nutritional status. JPEN J Parenter Enter Nutr 1993;17:513-518.

69 Serrou B, Cupissol D, Plagne R, Boutin P, Chollet P, Carcassonne Y, Michel FB: Follow-up of a randomized trial for oat cell carcinoma evaluating the efficacy of peripheral intravenous nutrition (PIVN) as adjunct treatment. Recent Results Cancer Res 1982;80:246-253.

-70 Koretz RL, Lipman T0, Klein S; American Gastroenterological Association: AGA technical review on parenteral nutrition. Gastroenterology 2001;121:970-1001.

71 Vashi PG, Dahlk S, Popiel B, Lammersfeld CA, Ireton-Jones C, Gupta D: A longitudinal study investigating quality of life and nutritional outcomes in advanced cancer patients receiving home parenteral nutrition. BMC Cancer 2014;14:593. 